\title{
A longitudinal, retrospective cohort study on the impact of roflumilast on exacerbations and economic burden among chronic obstructive pulmonary disease patients in the real world
}

\author{
This article was published in the following Dove Press journal: \\ International Journal of COPD \\ 7 October 2015 \\ Number of times this article has been viewed
}

\author{
Yin Wan' \\ Shawn $X$ Sun $^{2}$ \\ Shelby Corman' \\ Xingyue Huang ${ }^{2}$ \\ Xin Gao' \\ Andrew F Shorr ${ }^{3}$ \\ 'Health Economics and Modeling, \\ Outcomes Research, Pharmerit \\ International, Bethesda, MD, USA; \\ ${ }^{2} \mathrm{Health}$ Economics and Outcomes \\ Research, Forest Laboratories, LLC, \\ an affiliate of Actavis, Inc., Jersey City, \\ NJ, USA; ${ }^{3}$ Pulmonary Critical Care, \\ Washington Hospital Center and \\ Georgetown University, Washington, \\ DC, USA
}

\begin{abstract}
Background: Roflumilast is approved in the United States to reduce the risk of COPD exacerbations in patients with severe COPD. Exacerbation rates, health care resource utilization (HCRU), and costs were compared between roflumilast patients and those receiving other COPD maintenance drugs.

Methods: LifeLink ${ }^{\mathrm{TM}}$ Health Plan Claims Database was used to identify patients diagnosed with COPD who initiated roflumilast (roflumilast group) or $\geq 3$ other COPD maintenance drugs (non-roflumilast group) from May 1, 2011 to December 31, 2012. Patients must have been enrolled for 12 months before (baseline) and 3 months after (postindex) the initiation date, $\geq 40$ years old, not systemic corticosteroid dependent, and without asthma diagnosis at baseline. Difference-in-difference models compared change from baseline in exacerbations, HCRU (office, emergency visits, and hospitalizations), and total costs between groups, adjusting for baseline differences.

Results: A total of 14,211 patients (roflumilast, $n=710$; non-roflumilast, $n=13,501$ ) were included. During follow-up, the rate of overall exacerbations per patient per month decreased by $11.1 \%$ in the roflumilast group and increased by $15.9 \%$ in the non-roflumilast group $(P<0.001)$. After controlling for baseline differences, roflumilast-treated patients experienced a greater reduction in exacerbations ( 0.0160 fewer exacerbations per month, $P=0.01)$, numerically greater reductions in hospital admissions ( 0.003 fewer per month, $P=0.57)$, office visits $(0.46$ fewer per month, $P=0.26$ ), and total costs from baseline compared with non-roflumilast patients $(\$ 116$ less per month, $P=0.62$ ).
\end{abstract}

Conclusion: In a real-world setting, patients initiating roflumilast experienced reductions in exacerbations versus patients treated with other COPD medications.

Keywords: PDE-4 inhibitor, COPD, outcomes, health care resource utilization

\section{Introduction}

COPD is a progressive disease characterized by persistent airflow limitation, chronic and progressive dyspnea, cough, and sputum production and is often complicated by exacerbations. ${ }^{1}$ COPD affects approximately 24 million US adults, including 12.7 million diagnosed patients and 12 million undiagnosed, and is the third leading cause of death in the United States. ${ }^{2,3}$ The annual cost of COPD in 2010 was estimated at $\$ 49.9$ billion USD, with $\$ 29.5$ billion attributed to direct health care costs, in which hospital care accounted for the largest share. ${ }^{4}$

Treatment goals for patients with stable COPD include symptom relief, prevention of disease progression, and prevention and treatment of exacerbations. ${ }^{1}$ While symptom

\footnotetext{
Correspondence: Xin Gao Health Economics and Modeling, Outcomes Research, Pharmerit International, 4350 East West Highway, Suite 430, Bethesda, MD 208I4, USA

$\mathrm{Tel}+\mathrm{I} 2408211266$

Fax + I 24082 I I296

Email cgao@pharmerit.com
} 
relief is the primary target for pharmacologic therapy, prevention of exacerbations is also important because of the impact on lung function, health-related quality of life, hospitalization, and mortality. Recent COPD treatment guidelines emphasize the central role of bronchodilators, including $\beta_{2}$-agonists and anticholinergics, with drug selection depending on patient response and tolerability. Inhaled corticosteroids (ICS) have a more limited role for patients unable to achieve symptom control with bronchodilators alone. ${ }^{1}$

Roflumilast is a selective phosphodiesterase-4 inhibitor approved by the US Food and Drug Administration in 2011. It is indicated as a treatment to reduce the risk of COPD exacerbations in patients with severe COPD associated with chronic bronchitis and a history of exacerbations. ${ }^{5}$ No studies have compared roflumilast to other COPD maintenance medications, and there is very little real-world data on utilization, clinical, and economic outcomes associated with the use of roflumilast. We hypothesized that there were no differences in the relevant clinical and economic outcomes between roflumilast and other COPD maintenance medications. This retrospective cohort study was performed to test this hypothesis.

\section{Methods}

\section{Study design and data source}

This was a longitudinal, retrospective cohort study using US managed-care administrative data from the LifeLink PharMetrics Plus ${ }^{\mathrm{TM}}$ Health Plan Claims Database, which includes medical and pharmaceutical claims for over 150 million unique patients from over 90 health plans across the United States. The database includes inpatient and outpatient diagnoses, procedures, and prescription records. The prescription claims include National Drug Code, drug names, dose, strength, days' supply, and quantity dispensed. Dates are available for all medical services and prescriptions.
It also includes demographic variables, insurance information, and plan enrollment/eligibility data. We cleaned the obtained raw data by removing the duplicates and observations with missing values for key data elements, such as age, diagnosis date, and prescription date. The data in the claims databases are de-identified and fully compliant with the Health Insurance Portability and Accountability Act Privacy Regulations, exempting this study from an institutional review board approval requirement.

\section{Patient selection}

Selection of patients for the study is outlined in Figure 1. To be included in the analysis, patients had to have at least one medical claim with a primary diagnosis of COPD (International Classification of Diseases, Ninth Revision, Clinical Modification [ICD-9-CM] code 491.xx, 492.xx, or 496.xx) between May 1, 2010 and September 30, 2012; have initiated therapy with roflumilast or a third COPD maintenance medication between May 1, 2011 and September 30, 2012 (cohort selection period); and have continuous enrollment in the managed-care plan for at least 12 months before and 3 months after the index date, defined as the date of initiation of roflumilast or the first prescription of the third COPD maintenance medication. According to GOLD (Global initiative for chronic Obstructive Lung Disease) guidelines, ${ }^{1}$ roflumilast is recommended as the third maintenance agent for patients with severe COPD. To ensure disease severity was as comparable as possible between the comparison group (patients who did not receive roflumilast) and the group of patients who received roflumilast, patients who received at least three COPD agents were included as the comparison group and the start of the third COPD maintenance agent was defined as the index date.

Patients were excluded if they were younger than 40 years of age, had at least one medical claim with a diagnosis code

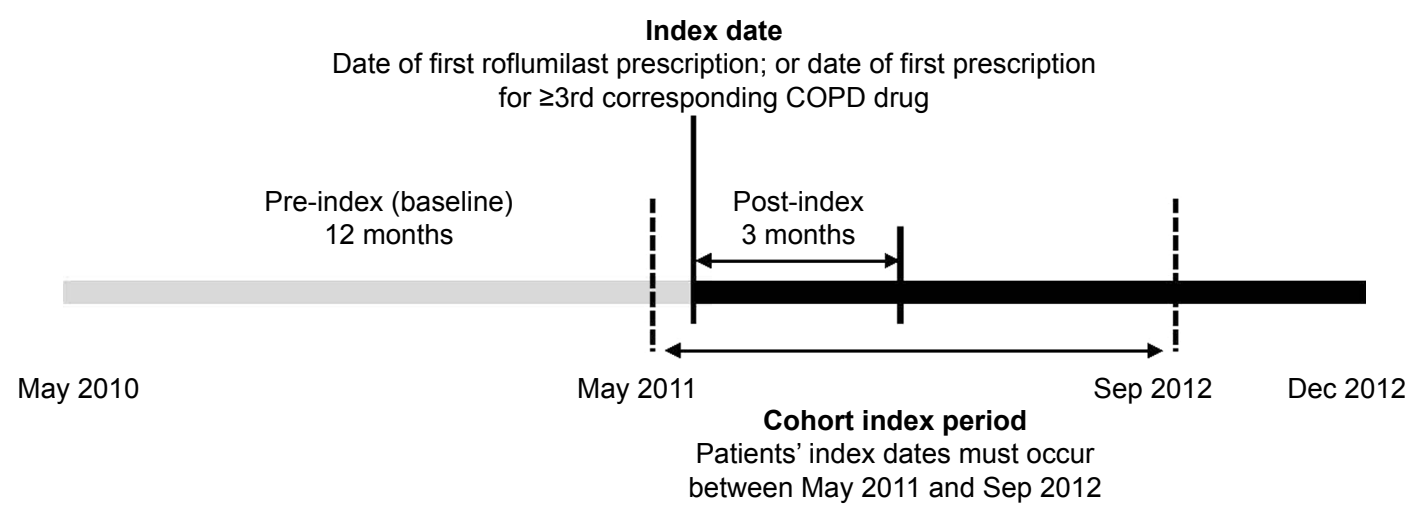

Figure I Study design and cohort selection. 
for cystic fibrosis (ICD-9-CM code 277.xx) or respiratory tract cancer (ICD-9-CM codes 160.xx-164.xx or 231.xx) during the study period, were corticosteroid dependent (defined as $\geq 182$ day supply of oral corticosteroids in the year before or after the index date), had at least one medical claim with a diagnosis of asthma (ICD-9-CM codes 493.0, 493.1, or 493.9) during the 12-month preindex period (ie, baseline period), or received roflumilast in combination with theophylline.

Study patients were separated into two cohorts: patients who initiated roflumilast during the cohort selection period (roflumilast group) and patients who initiated the third of three COPD maintenance medications during the cohort selection period (non-roflumilast group).

\section{Study measures}

Patient demographics included age at the index date, sex, insurance type, and census region. Clinical characteristics included comorbid conditions, reported as a prevalence per condition and used to calculate Charlson comorbidity index $;{ }^{6}$ number of COPD medications and days using COPD medications during the 12-month preindex period (termed as baseline period); number of COPD exacerbations (defined in the following paragraph); hospitalizations; and emergency department (ED) visits during the baseline period.

The primary outcome was the rate of moderate and severe COPD exacerbations per patient per month (PPPM) over the 3 months after the index date. Severe exacerbation was defined as a hospital admission with a primary diagnosis of COPD with acute exacerbation (ICD-9-CM codes 491.21, $491.22,493.22$, or 492.8) or a primary diagnosis of respiratory failure (ICD-9-CM codes 518.81, 518.82, or 518.84) combined with a secondary diagnosis of COPD with acute exacerbation or emphysema (491.0, 491.1, 491.21, 491.22, $491.8,491.9,492.0,492.8,493.22$, or 496). ${ }^{7}$ Moderate exacerbation was defined as a short course ( $\leq 14$ days) of oral corticosteroids within 7 days of an ED visit or an office visit with a COPD diagnosis (ICD-9-CM codes 491.xx, 492.xx, and 496.xx); an ED visit with a primary diagnosis of COPD with acute exacerbation or a primary diagnosis of respiratory failure combined with a secondary diagnosis of COPD with acute exacerbation or emphysema, as defined earlier; or an ambulatory claim with a diagnosis of COPD or another qualifying pulmonary condition (ICD-9-CM codes 136.3, 466-466.19, 480-486, 487.0, 490, 491.21, 491.22, 493.02, 493.12, 493.22, 493.92, 494.1, 506.0-506.3, 507-507.8, 511.0-511.1, 512-512.8, 517.1, 518.0, 518.81, 518.82, $518.84,770.84) .{ }^{8}$ Events occurring within 15 days of each other were counted as a single exacerbation.
Secondary outcomes included health care resource utilization (HCRU), including the number of inpatient hospitalization admissions, ED and office visits, and total health care costs. All HCRU and costs were presented as PPPM. Costs were inflated to 2012 values using the 2012 Consumer Price Index provided by the Bureau of Labor Statistics. ${ }^{9}$

\section{Statistical analyses}

Bivariate comparisons of patient demographics and baseline characteristics between the roflumilast and non-roflumilast groups were performed using Pearson chi-square tests for categorical variables and $t$-tests for continuous variables. Wilcoxon rank-sum tests were used to compare the HCRU and cost data between study groups because they usually have a skewed distribution. ${ }^{10}$

The differences between baseline and postindex exacerbation rates (PPPM), monthly HCRU, and monthly costs were calculated for each patient, and difference-in-difference (DID) linear regression models (Appendix) were used to adjust for covariates identified from the bivariate comparisons between roflumilast and non-roflumilast patients as described earlier. The DID model was used to control for observed baseline differences between treatment and control groups (eg, severity of disease), as well as the effects of all time-varying determinants of the outcomes (trend change in the outcomes over time) that are common to both study groups. ${ }^{11}$ It is worth noting that the DID model is based on an assumption that in the absence of treatment the difference between control and treatment groups would be constant or "fixed" over time. Analyses were performed using Statistical Analysis Software version 9.2.3 (SAS Institute, Cary, NC). For all analyses, statistical significance was defined as a $P$-value $<0.05$.

\section{Results \\ Patient sample}

Of 818,457 patients identified as having COPD using ICD-9 codes, 804,246 met at least one of the criteria for exclusion (Figure 2). The major reasons for exclusion were absence of claims for COPD maintenance medications during the cohort selection period $(n=501,556)$ and not receiving at least three maintenance COPD medications during the cohort selection period $(n=110,320)$. After these exclusions, there were 710 patients in the roflumilast group and 13,501 in the non-roflumilast group.

Demographic and clinical characteristics of the two groups are shown in Table 1. Patients in the roflumilast group were more likely to have comorbid congestive heart failure, had a 


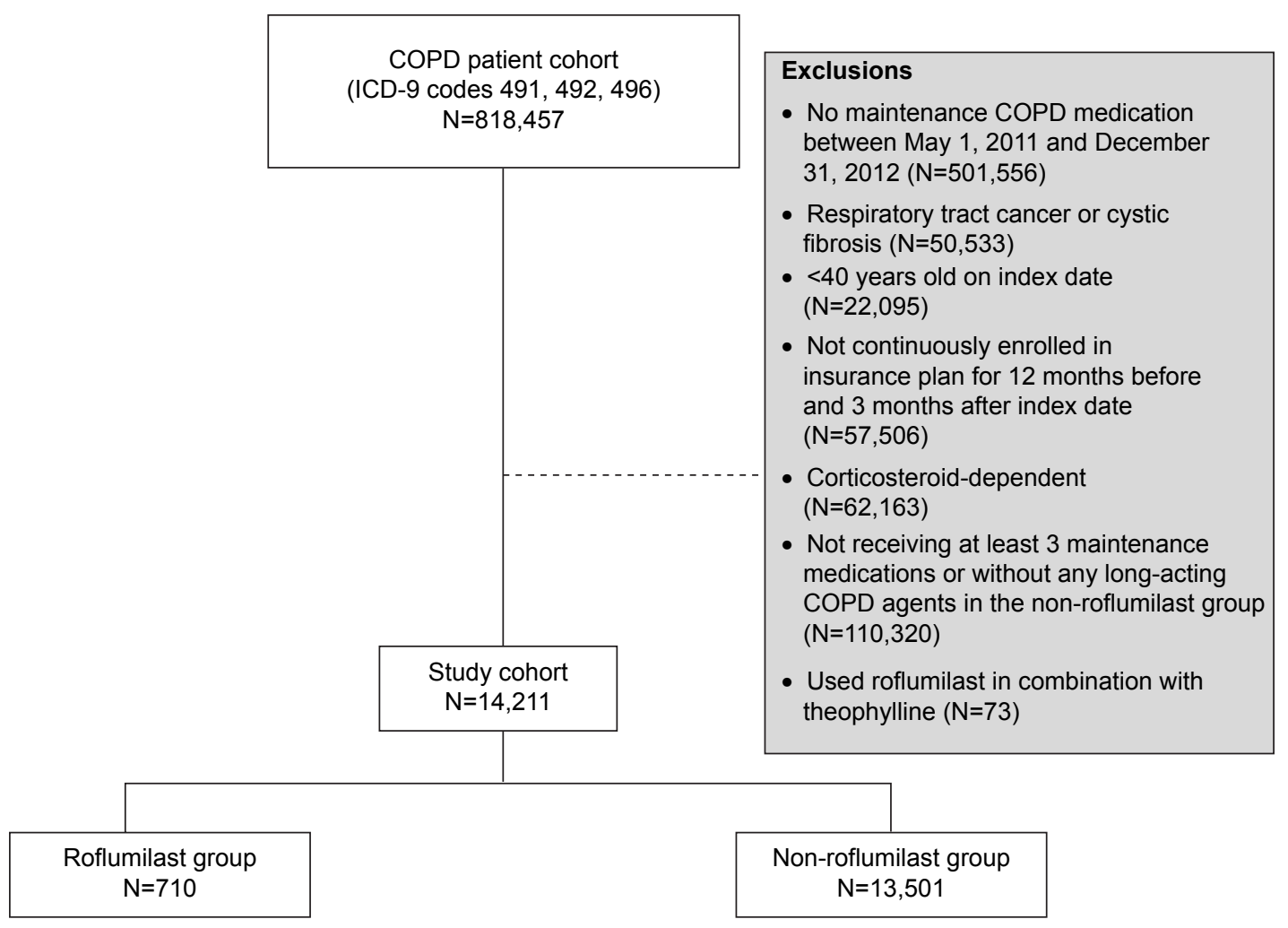

Figure 2 Flow chart of patient selection.

Abbreviation: ICD-9, International Classification of Diseases, Ninth Revision.

higher number of monthly exacerbations, were receiving more COPD medications at baseline, had more ED visits, and were more likely to be hospitalized during the 12-month preindex period. There were no statistically significant differences in age, sex, or Charlson comorbidity score between groups.

\section{COPD regimens exposed on the index date}

In the non-roflumilast group, the most common COPD regimen exposed on index date was a combination of a long-acting $\beta_{2}$-agonist (LABA) and ICS (47.2\%), followed

Table I Demographic and clinical characteristics at baseline

\begin{tabular}{|c|c|c|c|}
\hline Variable & Roflumilast $(n=7 \mid 0)$ & Non-roflumilast $(n=|3,50|)$ & $P$-value \\
\hline Age at index date (years), mean $\pm S D$ & $63.2 \pm 9.4$ & $63.3 \pm 10.4$ & 0.78 \\
\hline Male, n (\%) & $37 \mid(52)$ & $7,065(52)$ & 0.97 \\
\hline Charlson comorbidity score, mean \pm SD & $1.0 \pm 1.5$ & $1.0 \pm 1.5$ & 0.43 \\
\hline \multicolumn{4}{|l|}{ Comorbid conditions, $\mathrm{n}(\%)^{\mathrm{a}}$} \\
\hline Diabetes & $165(23)$ & $2,908(22)$ & 0.28 \\
\hline Congestive heart failure & $107(15)$ & $\mathrm{I}, 549(\mathrm{II})$ & 0.004 \\
\hline Cerebrovascular disease & $79(\mathrm{II})$ & $1,280(9)$ & 0.15 \\
\hline Peripheral vascular disease & $66(9)$ & $1,153(9)$ & 0.48 \\
\hline Chronic renal failure & $48(7)$ & $819(6)$ & 0.45 \\
\hline Malignancy (any) & $39(5)$ & $999(7)$ & 0.06 \\
\hline \multicolumn{4}{|l|}{ Monthly rate of exacerbations at baseline period (PPPM) } \\
\hline Moderate or severe & $0.1109 \pm 0.1331$ & $0.0529 \pm 0.0903$ & $<0.001$ \\
\hline Moderate & $0.0883 \pm 0.1117$ & $0.0435 \pm 0.0826$ & $<0.001$ \\
\hline Severe & $0.0227 \pm 0.0589$ & $0.0094 \pm 0.0315$ & $<0.001$ \\
\hline \multicolumn{4}{|l|}{ Resource utilization during baseline period } \\
\hline Number of COPD medications, mean \pm SD & $3.2 \pm 2.1$ & $2.6 \pm 2.1$ & $<0.001$ \\
\hline Days receiving COPD medications, mean \pm SD & $188 \pm 133$ & $166 \pm 143$ & $<0.001$ \\
\hline Number of ED visits, mean \pm SD & $0.5 \pm 2.0$ & $0.3 \pm 1.0$ & $<0.001$ \\
\hline At least one hospitalization, $\mathrm{n}(\%)$ & $558(79)$ & $9,697(72)$ & $<0.001$ \\
\hline
\end{tabular}

Note: anly those identified in $\geq 5 \%$ of patients were reported.

Abbreviations: ED, emergency department; SD, standard deviation; baseline, 12-month preindex period; PPPM, per patient per month. 
by a combination of those two classes plus a long-acting muscarinic antagonist (46.1\%). In the roflumilast group, $33.5 \%$ were receiving roflumilast in combination with a longacting muscarinic antagonist, LABA, and ICS, 30.4\% were receiving roflumilast monotherapy (of note, these patients may have had other COPD maintenance medications prior to index and discontinued to use these medications when initiating roflumilast), and $18.9 \%$ were receiving a combination of roflumilast, LABA, and ICS.

\section{Exacerbations}

Figure 3 shows the change in overall rate of exacerbation PPPM in the roflumilast and non-roflumilast groups from baseline. During the follow-up period, the monthly exacerbation rate decreased by $11.1 \%$ in the roflumilast group and increased by $15.9 \%$ in the non-roflumilast group (Figure 3A; $P<0.001$ for DID). While the rate of severe exacerbation PPPM decreased to a greater extent in the roflumilast group, this difference did not reach statistical significance (Figure 3B; $P=0.55)$. However, there was a significant difference in the rate of moderate exacerbation PPPM between groups, with the roflumilast group experiencing an $11.8 \%$ reduction and the non-roflumilast group having a $20.7 \%$ increase in exacerbations (Figure $3 C ; P=0.001$ ).

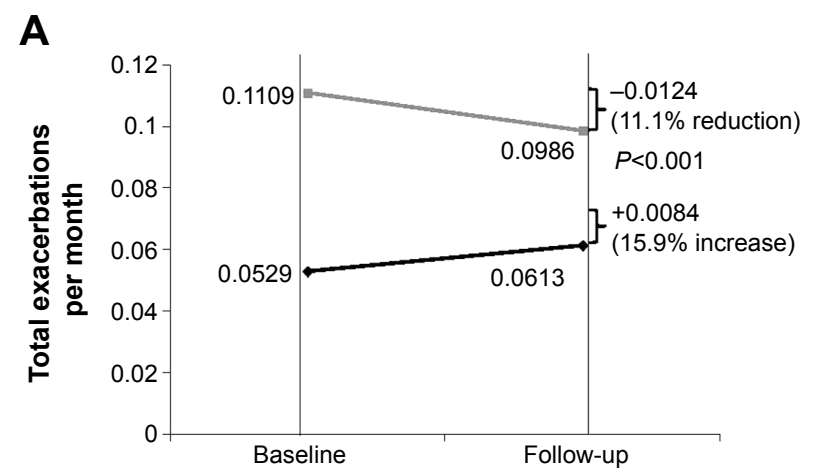

After controlling for the key covariates (age, sex, region, insurance, baseline number of COPD drugs, and Charlson comorbidity index) using a DID model approach, roflumilast patients still had a greater reduction in the rate of overall exacerbation $(\beta=-0.0160, P=0.01)$ and moderate exacerbation ( $\beta=-0.0149, P=0.01$ ) versus the non-roflumilast group. There was a numerically greater reduction in the rate of severe exacerbation in the roflumilast group after adjusting for covariates; however, the difference was not statistically significant $(\beta=-0.0012, P=0.63)$.

\section{Health care resource utilization}

Monthly number of office visits, ED visits, and inpatient hospitalization admissions at baseline and during follow-up are shown in Table 2. During both the baseline and follow-up periods, patients in the roflumilast group had more of each type of encounter than patients in the non-roflumilast group. Both treatment groups had increased office visits, ED visits, and hospitalizations during the follow-up period compared to the baseline period. However, the unadjusted results showed that the change from baseline was significantly different between the roflumilast and non-roflumilast groups for monthly rate of hospital admissions (0.002 \pm 0.152 vs $0.005 \pm 0.123, P=0.024)$ and office visits $(0.081 \pm 0.938$ vs $0.122 \pm 0.889, P=0.01)$, but not for the ED visits. After

B

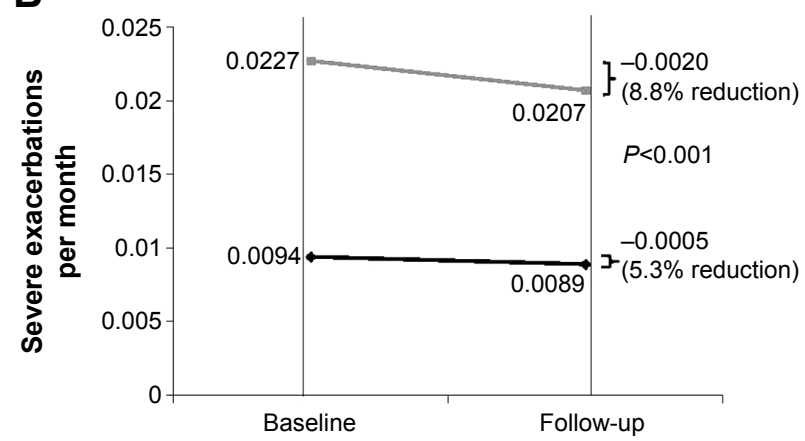

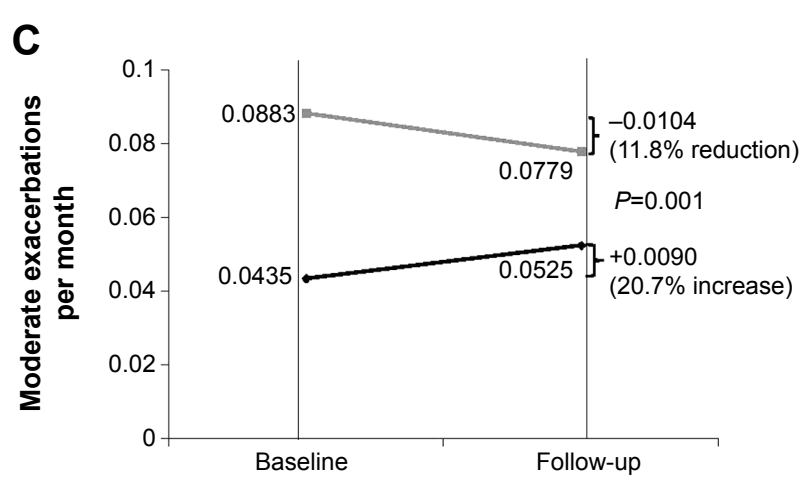

$\rightarrow$ Roflumilast $(\mathrm{n}=710)$

$\rightarrow$ Non-roflumilast $(n=13,501)$

Figure 3 Monthly chronic obstructive pulmonary disease exacerbations: (A) total exacerbations, (B) severe exacerbations, (C) moderate exacerbations. Notes: Baseline refers to monthly exacerbation rate during the 12-month preindex period; follow-up refers to monthly exacerbation rate during the 3-month follow-up period. 
Table 2 Monthly health care resource utilization

\begin{tabular}{|c|c|c|c|}
\hline Health care resource utilization & Roflumilast $(n=7 \mid 0)$ & Non-roflumilast $(n=|3,50|)$ & $P$-value \\
\hline \multicolumn{4}{|l|}{ Office visits } \\
\hline Baseline period, mean \pm SD & $0.370 \pm 0.575$ & $0.316 \pm 0.559$ & $<0.001$ \\
\hline Follow-up period, mean \pm SD & $0.45 I \pm 0.973$ & $0.438 \pm 0.978$ & 0.83 \\
\hline Change from baseline, mean $\pm S D$ & $0.08 I \pm 0.938$ & $0.122 \pm 0.889$ & 0.01 \\
\hline \multicolumn{4}{|l|}{ Emergency department visits } \\
\hline Baseline period, mean \pm SD & $0.042 \pm 0.166$ & $0.028 \pm 0.082$ & 0.06 \\
\hline Follow-up period, mean \pm SD & $0.05 I \pm 0.197$ & $0.035 \pm 0.154$ & 0.02 \\
\hline Change from baseline, mean $\pm S D$ & $0.009 \pm 0.233$ & $0.007 \pm 0.147$ & 0.80 \\
\hline \multicolumn{4}{|l|}{ Inpatient hospitalizations } \\
\hline Baseline period, mean \pm SD & $0.041 \pm 0.085$ & $0.027 \pm 0.061$ & $<0.001$ \\
\hline Follow-up period, mean \pm SD & $0.043 \pm 0.145$ & $0.032 \pm 0.121$ & 0.03 \\
\hline Change from baseline, mean $\pm S D$ & $0.002 \pm 0.152$ & $0.005 \pm 0.123$ & 0.02 \\
\hline
\end{tabular}

Note: The result data represent average resource use per patient per month.

Abbreviations: Baseline, 12-month preindex period; SD, standard deviation.

controlling for key covariates using DID models, roflumilast was associated with fewer hospital admissions $(\beta=-0.003$, $P=0.57)$ and office visits $(\beta=-0.46, P=0.26)$; however, the differences were not statistically significant.

\section{Health care costs}

Table 3 shows total monthly health care costs in the roflumilast and non-roflumilast groups during the baseline and follow-up periods. During the baseline and follow-up periods, health care costs were significantly higher in the roflumilast group. The detailed cost component data were shown in Table S1. Costs increased for both groups from the baseline to the follow-up period, with no significant difference in the change from baseline between groups. After controlling for the key covariates using a DID model, the total cost increase was $\$ 116$ more for the control of patients not treated with roflumilast versus patients treated with roflumilast $(P=0.62)$.

\section{Discussion}

This study found that patients initiating roflumilast had more severe COPD in that they had a higher number of monthly exacerbations, received more COPD medications, and used more HCRU than patients initiating other COPD maintenance medications (based on the observation during the baseline period). Exacerbation rates were significantly improved for patients treated with roflumilast, with an $11 \%$ decrease in the rate of exacerbations in the roflumilast group and a $16 \%$ increase in the non-roflumilast group (a relative $27 \%$ reduction). After controlling for baseline differences using a DID model approach, the significant differences in exacerbation rates between groups remained. After controlling for covariates using DID models, changes in hospital admissions and total costs did not differ significantly between the roflumilast and non-roflumilast groups. The cost analysis in our study focused on the overall cost (cost component shown in Table S1). In order to further understand how roflumilast impacts different cost components, future studies should examine the COPD- or exacerbation-related costs by component, especially when the roflumilast was used as an add-on treatment following the GOLD guidance.

Randomized controlled trials evaluating the efficacy and safety of roflumilast in patients with COPD found significant between-group differences in moderate or severe exacerbation rates (a $17 \%$ reduction, $P=0.0003$ ); however, these trials were placebo-controlled and 6 months ${ }^{12}$ or 1 year ${ }^{13}$ in duration. Significant differences in the rate of moderate, but not severe, exacerbations were initially found in two pivotal 1-year trials, ${ }^{12,13}$ which may be due to a lack of statistical power given the relatively small sample sizes of clinical trial data. Similarly, in the current study, there may not have been

Table 3 Monthly total health care costs $(\$)$

\begin{tabular}{|c|c|c|c|}
\hline Total costs & Roflumilast (n=7|0) & Non-roflumilast $(n=\mid 3,50 I)$ & P-value \\
\hline Baseline period, mean $\pm S D$ & $2,420 \pm 3,862$ & $1,950 \pm 3,225$ & $<0.001$ \\
\hline Follow-up period, mean \pm SD & $2,85 \mathrm{I} \pm 5,327$ & $2,472 \pm 6,252$ & $<0.001$ \\
\hline Change from baseline, mean \pm SD & $432 \pm 5,244$ & $522 \pm 6,047$ & 0.34 \\
\hline
\end{tabular}

Note: The result data represent average cost per patient per month.

Abbreviations: Baseline, 12-month preindex period; SD, standard deviation. 
sufficient power to detect a significant difference in the change in severe exacerbation rates between groups. Relatively, the cohort of patients who received roflumilast was large in this retrospective cohort study; however, there may be large treatment variations from patients in real-world settings compared to the strict treatment regimens of a clinical trial. Additionally, severe exacerbations are relatively rare events, which may further reduce the power of the analysis for this outcome.

As GOLD recommended, roflumilast can be used an add-on treatment for patients with COPD in stages 3/4 (forced expiratory volume in 1 second $\left(\mathrm{FEV}_{1}\right)<50 \%$ predicted after bronchodilatation) and frequent exacerbations despite a longacting bronchodilator treatment. It was found that the COPD drugs usage before initiating roflumilast varies in our study. It may be informative to explore the subset of patients who strictly followed the GOLD guidance (ie, those receiving ICS and a LABA or other long-acting bronchodilators prior to the use of roflumilast) using the real-world data. Future studies are warranted to assess the outcomes of those patients who have used ICS and long-acting bronchodilator within certain window prior to initiating roflumilast using a large sample.

Previous studies examined the resource utilization and health care costs associated with exacerbations among COPD patients. ${ }^{14-17}$ In a US managed-care population initiating COPD maintenance medications, AbuDagga et al found that exacerbation rates continued to be high, resulting in an estimated annual cost of $\$ 25,747$ in the overall population and $\$ 29,861$ in the patients with history of one or more exacerbations. ${ }^{14}$ In this study, calculated total monthly costs during the 3-month follow-up period were $\$ 2,472$ and $\$ 2,851$ for non-roflumilast and roflumilast group, respectively, which is higher than the AbuDagga study ${ }^{14}$ and likely due to the selection of patients with more severe COPD. Darnell et al reported an annual 3.07 clinic visits, $0.15 \mathrm{ED}$ visits, and 0.41 hospitalizations per person per year, among COPD patients, calculated using a large administrative database. ${ }^{15}$ The resource utilization reported here was similar or slightly higher than data in the Darnell et al study ${ }^{15}$ and again, this discrepancy may be due to the selection of patients with more severe COPD. Of note, our study examined the economic burden associated with COPD medications from the payer's perspective; indirect costs, such as productivity loss, were not included, and thus, cost data may be conservative estimates.

COPD exacerbations result in increases in resource utilization, especially for severe exacerbations. ${ }^{9,18,19}$ Consistent with previous studies, the current work found that reduced exacerbation rates among COPD patients were associated with reduced all-cause resource utilization and costs from a managed-care payer's perspective. Therefore, it is vital for physicians and payers to be aware that preventing COPD exacerbations through appropriate treatments could minimize the need for hospitalization and other medical resource use. In addition, previous research also suggested that reducing exacerbation frequency may improve the quality of life among patients with COPD. ${ }^{20}$

Strengths of this study include the use of a robust national commercial insurance database with a longitudinal data structure that allows for tracking of both inpatient and outpatient diagnoses and procedures as well as outpatient prescription records. The availability of prescription claims provided rich information on treatment patterns and medication use as an indicator of exacerbation frequency. The use of DID models controlled for significant baseline differences in study populations, which is important as there is potential for selection bias due to the observational study design.

Our study has several limitations and it is important to interpret our results in the context of these limitations. First, some clinical details such as lung function parameters are not available in the database. The cohort selection criteria is based on the use of COPD maintenance treatments (ie, patients who initiated roflumilast or a third COPD drug), which may identify more severe patients by the criteria itself. Second, the definition of COPD exacerbations was based entirely on claims data rather than patient symptoms. The study by Stein et al suggested that algorithms based on ICD-9-CM codes may undercount the acute exacerbation for COPD. ${ }^{21}$ The exacerbation rates among patients receiving roflumilast were similar to those reported in randomized trials, ${ }^{12,13,22}$ which validate our results. Third, the study sample for the roflumilast group was restricted to those with insurance covering roflumilast. Because data were available only for commercially insured patients, the results may not be generalizable to older patients covered by Medicare. However, the mean age of patients in our study was only slightly lower than that of patients in randomized trials (63 years vs 65 years). ${ }^{12,13}$ Fourth, we used a DID model that mimicked an experimental study and controlled for the baseline difference between study groups. Our adjusted DID regressions were based on an assumption that in the absence of treatment, the difference between control (without roflumilast) and treatment (with roflumilast) groups would be constant or "fixed" over time. However, in reality, it is possible that the roflumilast group was inherently more likely to experience a reduction in exacerbation rate compared to the non-roflumilast group due to having higher exacerbation rates at baseline. In this study, we observed a decreased overall exacerbation rate in the roflumilast group 
contrasted with an increased exacerbation rate in the nonroflumilast group. The magnitude of the difference suggests that the observed results cannot be attributed exclusively to unobserved confounders. Fifth, it is challenging to adjust for the difference in adherence in the patients without roflumilast. Patients' adherence to treatments, especially to the combination therapy, may change quickly over time because patients may discontinue some drugs after the symptoms improve. It will be important for future studies to control for the adherence if a specific comparator drug is chosen. Sixth, our results may not be able to identify the seasonal effect as the follow-up duration covers only 3 months. ${ }^{23}$ However, both study groups have the same index period so the difference in the exacerbation outcomes between the two study groups may not be biased. Finally, we did not have a large sample of the roflumilast-treated group as roflumilast is only recently approved by the US Food and Drug Administration (February 2011). This may affect the statistical power and our study may not be sufficient to determine the long-term effects of roflumilast on exacerbations, HCRU, and costs.

\section{Conclusion}

Patients with COPD-initiating roflumilast treatment had greater reductions in exacerbation rates in the 3 months after the new therapy was added than patients initiating other COPD maintenance medications. We also found a numerically smaller increase from baseline in the monthly rates of hospital admissions, office visits, and monthly total costs between patients treated with roflumilast versus patients not treated with roflumilast. Future studies using alternative methods such as patient survey or chart review - are warranted to further evaluate the impact of roflumilast on clinical outcomes, HCRU, and costs within a longer follow-up period.

\section{Acknowledgments}

This study was funded by Forest Research Institute, Inc., a wholly owned subsidiary of Forest Laboratories, Inc. Prescott Medical Communications Group (Chicago, IL, USA) assisted with editing, circulation of drafts among the authors, and formatting of the manuscript for submission.

\section{Disclosure}

YW, SC, and XG are employees of Pharmerit International, an independent contract research organization that received a consulting fee from Forest Research Institute, Inc., related to the database analysis and manuscript development. SXS is an employee and XYH is a former employee of Forest Inc.
AFS is a physician at the Washington Hospital Center and Georgetown University, Washington, DC, who received a consulting fee from Forest Research Institute, Inc. This study was designed jointly by Pharmerit International and the study sponsor, Forest Research Institute. All authors contributed to the review and interpretation of the results and the development and critical review of the manuscript. All authors had full access to the data used for this study, take full responsibility for the integrity of the data, and were not financially compensated for their authorship of the manuscript.

\section{References}

1. Vestbo J, Hurd SS, Agusti AG, et al. Global strategy for the diagnosis, management, and prevention of chronic obstructive pulmonary disease: GOLD executive summary. Am J Respir Crit Care Med. 2013;187(4):347-365.

2. Health, United States. With Special Feature on Death and Dying. 2010. Available from: http://www.cdc.gov/nchs/data/hus/hus10. pdf\#specialfeature

3. Hoyert DL, Xu J. Deaths: preliminary data for 2011. Natl Vital Stat Rep. 2012;61(6):1-65.

4. Mapel DW, Hurley JS, Frost FJ, Petersen HV, Picchi MA, Coultas DB. Health care utilization in chronic obstructive pulmonary disease: a case-control study in a health maintenance organization. Arch Intern Med. 2000;160(17):2653.

5. DALIRESP ${ }^{\circledR}$ (Roflumilast) [Package Insert]. St Louis, MO: Forest Pharmaceuticals, Inc. Available from: http://frx.com/pi/Daliresp_pi.pdf

6. Deyo RA, Cherkin DC, Ciol MA. Adapting a clinical comorbidity index for use with ICD-9-CM administrative databases. $J$ Clin Epidemiol. 1992;45(6):613-619.

7. Lindenauer PK, Pekow PS, Lahti MC, Lee Y, Benjamin EM, Rothberg MB. Association of corticosteroid dose and route of administration with risk of treatment failure in acute exacerbation of chronic obstructive pulmonary disease. JAMA. 2010;303(23):2359-2367.

8. Mapel DW, Dutro MP, Marton JP, Woodruff K, Make B. Identifying and characterizing COPD patients in US managed care. A retrospective, cross-sectional analysis of administrative claims data. BMC Health Serv Res. 2011;11:43.

9. Dalal AA, Christensen L, Liu F, Riedel AA. Direct costs of chronic obstructive pulmonary disease among managed care patients. Int $J$ Chron Obstruct Pulmon Dis. 2010;5:341.

10. Barber J, Thompson S. Multiple regression of cost data: use of generalised linear models. J Health Serv Res Policy. 2004;9(4):197-204.

11. Lichtenberg FR, Sun SX. The impact of Medicare part D on prescription drug use by the elderly. Health Aff. 2007;26(6):1735-1744.

12. Fabbri LM, Calverley P, Izquierdo-Alonso JL, et al. Roflumilast in moderate-to-severe chronic obstructive pulmonary disease treated with long-acting bronchodilators: two randomised clinical trials. Lancet. 2009;374(9691):695-703.

13. Calverley P, Rabe KF, Goehring U-M, Kristiansen S, Fabbri LM, Martinez FJ. Roflumilast in symptomatic chronic obstructive pulmonary disease: two randomised clinical trials. Lancet. 2009;374(9691): 685-694.

14. AbuDagga A, Sun SX, Tan H, Solem CT. Healthcare utilization and costs among chronic bronchitis patients treated with maintenance medications from a US managed care population. J Med Econ. 2013;16(3):421-429.

15. Darnell K, Dwivedi AK, Weng Z, Panos RJ. Disproportionate utilization of healthcare resources among veterans with COPD: a retrospective analysis of factors associated with COPD healthcare cost. Cost Eff Resour Alloc. 2013;11(1):13. 
16. Johannesdottir SA, Christiansen CF, Johansen MB, et al. Hospitalization with acute exacerbation of chronic obstructive pulmonary disease and associated health resource utilization: a population-based Danish cohort study. J Med Econ. 2013;16(7):897-906.

17. Pasquale MK, Sun SX, Song F, Hartnett HJ, Stemkowski SA. Impact of exacerbations on health care cost and resource utilization in chronic obstructive pulmonary disease patients with chronic bronchitis from a predominantly Medicare population. Int J Chron Obstruct Pulmon Dis. 2012;7:757.

18. Donaldson G, Seemungal T, Patel I, Lloyd-Owen S, Wilkinson T, Wedzicha J. Longitudinal changes in the nature, severity and frequency of COPD exacerbations. Eur Respir J. 2003;22(6):931-936.

19. Mittmann N, Kuramoto L, Seung S, Haddon J, Bradley-Kennedy C, Fitzgerald J. The cost of moderate and severe COPD exacerbations to the Canadian healthcare system. Respir Med. 2008;102(3):413-421.

20. Llor C, Molina J, Naberan K, Cots J, Ros F, Miravitlles M. Exacerbations worsen the quality of life of chronic obstructive pulmonary disease patients in primary healthcare. Int J Clin Pract. 2008;62(4):585-592.
21. Stein BD, Bautista A, Schumock GT, et al. The validity of international classification of diseases, ninth revision, clinical modification diagnosis codes for identifying patients hospitalized for COPD exacerbations validity of diagnosis codes in COPD exacerbations. Chest. 2012;141(1):87-93.

22. Calverley PM, Sanchez-TorilF, McIvor A, TeichmannP,BredenbroekerD, Fabbri LM. Effect of 1-year treatment with roflumilast in severe chronic obstructive pulmonary disease. Am J Respir Crit Care Med. 2007;176(2):154-161.

23. Rabe KF, Fabbri LM, Vogelmeier C, et al. Seasonal distribution of COPD exacerbations in the prevention of exacerbations with tiotropium in COPD trial. Chest. 2013;143(3):711-719. 


\section{Supplementary material}

Table SI Monthly total health care costs and cost by component $(\$)$

\begin{tabular}{|c|c|c|c|}
\hline Cost variable & Non-roflumilast $(n=\mid 3,501)$ & Roflumilast ( $n=7 \mid 0)$ & $P$-value \\
\hline \multicolumn{4}{|l|}{ Baseline costs } \\
\hline Total cost, mean \pm SD & $1,950 \pm 3,225$ & $2,420 \pm 3,862$ & $<0.001$ \\
\hline Inpatient costs, mean \pm SD & $810 \pm 2,295$ & $1,030 \pm 2,417$ & $<0.001$ \\
\hline Outpatient costs, mean \pm SD & $56 I \pm 1,332$ & $715 \pm 1,964$ & $<0.001$ \\
\hline ER costs, mean $\pm S D$ & $22 \pm 133$ & $33 \pm 224$ & 0.09 \\
\hline COPD drug costs, mean \pm SD & $259 \pm 518$ & $294 \pm 412$ & $<0.001$ \\
\hline \multicolumn{4}{|l|}{ Follow-up costs } \\
\hline Total cost, mean \pm SD & $2,472 \pm 6,252$ & $2,85 I \pm 5,327$ & $<0.001$ \\
\hline Inpatient costs, mean \pm SD & $1,055 \pm 5,219$ & $\mathrm{I}, 084 \pm 2,766$ & $<0.001$ \\
\hline Outpatient costs, mean \pm SD & $720 \pm 2,148$ & $|, 049 \pm 3,85|$ & $<0.001$ \\
\hline ER costs, mean $\pm S D$ & $25 \pm 183$ & $42 \pm 262$ & 0.014 \\
\hline COPD drug costs, mean \pm SD & $234 \pm 521$ & $24 I \pm 373$ & 0.011 \\
\hline
\end{tabular}

Notes: The result data represent average cost per patient per month. The total cost is more than the sum of inpatient, outpatient, ER, and COPD drug costs because there are other types of cost components not shown in this table.

Abbreviations: Baseline, I2-month preindex period; COPD, chronic obstructive pulmonary disease; SD, standard deviation; ER, emergency room.

\section{Publish your work in this journal}

The International Journal of COPD is an international, peer-reviewed journal of therapeutics and pharmacology focusing on concise rapid reporting of clinical studies and reviews in COPD. Special focus is given to the pathophysiological processes underlying the disease, intervention programs, patient focused education, and self management protocols.
Dovepress

This journal is indexed on PubMed Central, MedLine and CAS. The manuscript management system is completely online and includes a very quick and fair peer-review system, which is all easy to use. Visit $\mathrm{http}: / /$ www.dovepress.com/testimonials.php to read real quotes from published authors. 